Aplikasi Citra Satelit ...

\title{
APLIKASI CITRA SATELIT LANDSAT 8 UNTUK IDENTIFIKASI DAERAH PROSPEK PANAS BUMI DAERAH SONGGORITI BATU DAN SEKITARNYA
}

\author{
B Harjo Agung, Alifiansyah Faizal, Arwin Anggi, Ayi Syaeful Bahri, Utama Widya \\ Teknik Geofisika, Fakultas Teknik Sipil, Lingkungan dan Kebumian, Institut Teknologi Sepuluh Nopember Surabaya \\ e-mail : tricahyoagung18@gmail.com
}

\begin{abstract}
Abstrak. Dalam menentukan daerah prospek panas bumi, pemetaan permukaan diperlukan untuk menentukan titik atau area prospek yang dapat dikaji bawah permukaannya. Pemetaan permukaan bumi dapat dilakukan menggunakan citra satelit landsat 8. Penelitian ini dilakukan untuk memetakan struktur, temperatur permukaan tanah dan batuan permukaan. Hasil yang didapatkan dikorelasikan dengan geologi. Data citra yang digunakan pada penelitian ini adalah citra satelit landsat 8 dengan band 4, band 5 , band 7 dan band 11. Untuk memperoleh informasi struktur bawah permukaan dilakukan komposit pada band 4 , band 5, band 7 . Untuk menentukan temperatur permukaan digunakan band 11 yang dikoreksi atmosfer terlebih dahulu untuk menghilangkan pengaruh atmosfer dalam wilayah termal. Untuk menentukan titik batuan teralterasi maka dilakukan komposit band 7 , band 4 , band 2 . Hasil yang didapatkan adalah struktur bawah permukaan, temperature permukaan dan batuan permukaan tanah.
\end{abstract}

Kata Kunci : Citra Satelit 8 , struktur, alterasi, temperatur permukaan tanah

\begin{abstract}
Research has been conducted with the aim of mapping structure, surface temperature, surface rock and geological analysis to determine the geothermal prospect of Songgoriti, Batu and surrounding areas with Landsat 8. On this research, Data are bands 4,5,7 and 11. To structural information, a composite of 4,5.7 seconds was used to obtain the thermal satellite used by band 11 corrected bands to eliminate atmospheric influence in the thermal region. To determine the point of alteration of rocks then made a composite band 7, band 4, band 2 . The result is a structural map, surface temperature map and surface rocks.
\end{abstract}

Keywords : Satellite Imagery 8, geomorphology, geothermal manifestation, ground surface temperature

\section{PENDAHULUAN}

Salah satu kegiatan eksplorasi panas bumi berupa identifikasi manifestasi panas bumi seperti air panas dan alterasi batuan. Apabila identifikasi dilakukan dengan cara langsung ke lapangan tanpa adanya petunjuk apapun, maka kegiatan eksplorasi akan memakan waktu dan biaya yang tidak sedikit. Diperlukan suatu metode yang dapat memberikan informasi awal untuk mengidentifikasi daerah atau titik prospek panas bumi yaitu metode penginderaan jauh. Oleh karena itu pada penelitian ini dilakukan analisis daerah prospek panas bumi daerah Songgoriti Batu dan sekitarnya melalui penginderaan jauh. Proses pemetaan ini dilakukan dengan cara menganalisis struktur yang tampak ke permukaan, peta temperatur permukaan tanah dan batuan permukaan. Data citra yang digunakan adalah citra satelit 8 karena memiliki kemudahan dalam mendapatkan data dan juga dalam pengolahannya dengan area cakupan yang luas. (Purwanto dkk, 2016; Utama dkk, 2012)

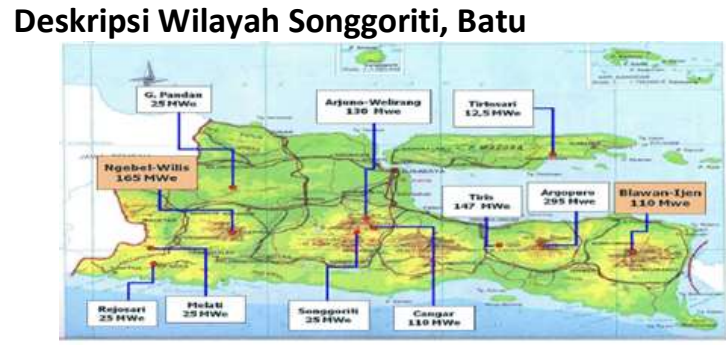

Gambar 1. Peta Potensi Panas Bumi Jawa Timur

Songgoriti terletak di kelurahan Songgokerto, Kecamatan Batu, Kota Batu, Jawa Timur. Daerah ini terletak di sebelah barat Kota Batu dan merupakan daerah yang memiliki potensi panas bumi sebesar 25Mwe seperti pada Gambar 1 (ESDM, 2013). Lokasi penelitian terletak pada koordinat $07^{\circ} 51^{\prime} 44,30^{\prime \prime}$ - 07 $52^{\prime} 02,97^{\prime \prime}$ LS dan $112^{\circ} 29^{\prime} 31,40^{\prime \prime}$ $112^{\circ} 29^{\prime} 59,9^{\prime \prime}$ BT.

\section{GEOLOGI DAERAH PENELITIAN}

Daerah Batu dan sekitarnya termasuk dalam pegunungan dan perbukitan vulkanik berumur kuarter. 


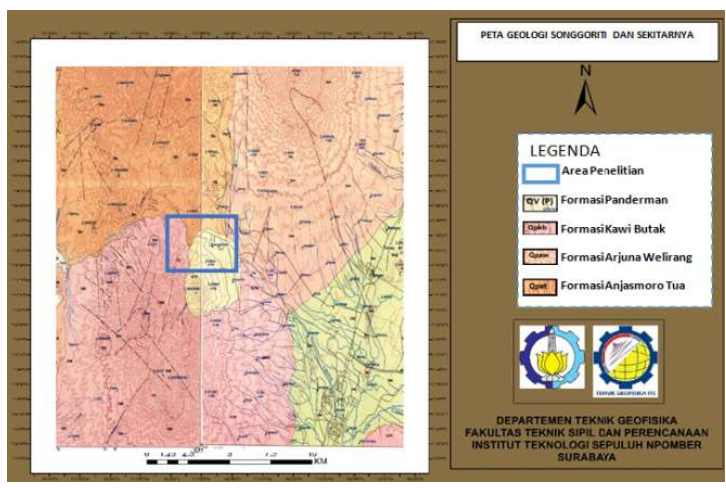

Gambar 2. Peta Geologi Batu (Modifikasi Lembar KediriBatu,Santosa1992)

Berdasarkan Peta Geologi Lembar Kediri dan lembar Batu pada Gambar 2, daerah Songgoriti berada di kaki gunung Butak - Kawi, Gunung Arjuna-Welirang, Gunung Anjasmara Tua dan Panderman. Aktivitas Gunung Anjasmara Tua (Qpat) yang berumur Plistosen Awal - Tengah menghasilkan breksi gunung-api, breksi tuf, tuf dan lava. Pada akhir plistosen terjadi aktivitas vulkanik Gunung Kawi - Butak (Qpvp) yang berada di selatan songgoriti dan Gunung Arjuna Welirang (Qvaw) berada di sisi timur dan utara songgoriti. Hasil letusan Gunung api Gunung Kawi - Butak (Qpvp) berupa lava andesit, tuf, dan breksi vulkanik. Sedangkan Gunung Arjuna - welirang (Qvaw) berupa breksi gunung api, lava, breksi tufan dan tuf. Pada umur Holosen terbentuk Gunung Panderman yang berada di selatan Songgoriti. Hasil endapan aktifitas Gunung Panderman (Qvp) ini berupa breksi gunungapi, tuf breksi, lava dan tuf. Struktur geologi yang mempengaruhi daerah ini berupa sesar - sesar mendatar di bagian selatan dan sebagian berupa sesar turun akibat dari letusan gunung api. Sesar - sesar inilah yang membawa manisfestasi dari dalam keluar permukaan (Nuha, 2012)

\section{Konversi ke Temperatur}

Data band termal dapat dikonversi dari sensor spectral radiance kedalam sensor temperatur. Sensor temperatur mengasumsikan bahwa permukaan bumi adalah black body (spectral emisivitas 1). Persamaan konversi dari sensor spectral radiance kedalam temperatur adalah :

$$
T=\frac{K 2}{\ln \left(\frac{K 1}{L_{T}}+1\right)}
$$

keterangan:

$\mathrm{T}$ adalah temperatur efektif sensor (K), K2 adalah konstanta kalibrasi 2 (K), K1 adalah konstanta kalibrasi $1\left(\mathrm{~W} /\left(\mathrm{m}^{2} \mathrm{sr} \mu \mathrm{m}\right), \mathrm{L}_{T}\right.$ adalah spectral radiance pada sensor $\left(\mathrm{W} /\left(\mathrm{m}^{2} \mathrm{sr} \mu \mathrm{m}\right)\right.$ (Sofani, 2011)

\section{Koreksi Radiometrik dan koreksi Geometrik}

Koreksi geometrik diperlukan dalam analisis citra satelit landsat 8 untuk mengkoreksi kesalahan atau eror yang diakibatkan pergerakan satelit ketika mengorbit. Semua data digital remote sensing satelit mengandung kesalahan geometrik (systematic and unsystematic error) (Berstein, 2013). Pada penelitian ini, kesalahan tersebut dapat dikoreksi dengan menggunakan variabel yang diketahui dalam internal sensor Dalam koreksi geometrik dikenal dua jenis metode yaitu rektifikasi dan ortho-rektifikasi.

Rektifikasi merupakan proses koreksi yang sesuai dengan koordinat peta, GPS atau citra-citra lainnya yang sudah terkoreksi. Sedangkan orthorektifikasi merupakan proses koreksi geometrik dengan memasukan data ketinggian dan informasi posisi platform satellite (Rina, 2011). Sebelum dilakukan koreksi geometrik, dilakukan terlebih dahulu melalui proyeksi peta. dibutuhkan penyamaan posisi antara satu citra dengan citra lainnya dengan sistem koordinat DMS (Degree minute second) dalam WGS84 (Sukartono, 2015)

Pada penelitian ini dilakukan juga koreksi radiometrik yang bertujuan untuk memperbaiki nilai piksel agar sesuai dengan keadaan sebenarnya dengan mempertimbangkan faktor gangguan atmosfer sebagai sumber kesalahan utama. Efek atmosfer menyebabkan nilai pantulan obyek dipermukaan bumi yang terekam oleh sensor menjadi beda dengan nilai aslinya, tetapi menjadi lebih besar oleh karena adanya hamburan atau lebih kecil karena proses serapan (Projo, 2016)

\section{Konversi Digital Number ke TOA Radiance}

Data citra satelit 8 yaitu band 11 digunakan untuk menghitung temperatur permukaan tanah. Persamaan yang digunakan untuk mengkonversi digital number (DN) ke radiance angkasa atau top of atmosphere (TOA) radiance adalah sebagai berikut :

$$
L_{\lambda}=\left(\frac{L M A X_{\lambda}-L M I_{\lambda}}{Q_{\text {cal max }}-Q_{\text {cal min }}}\right)\left(D N-Q_{\text {cal min }}\right)+
$$


$L_{\lambda}$ adalah TOA radiance pada lubang bidik kamera sensor dalam $\mathrm{W} / \mathrm{m} 2^{*} \mathrm{sr} * \mu \mathrm{m}$, Lmax adalah TOA radiance terskala terhadap Qcalmax (Sofani, 2011) Koreksi atmosfer diperlukan untuk pengolahan citra termal. Hal ini dikarenakan sinyal emisi yang meninggalkan target di permukaan akan dilemahkan dan dikuatkan oleh atmosfer. Efek atmosfer pada citra termal dapat dihilangkan dengan mengkonversi radiance TOA ke radiance yang meninggalkan permukaan. (Barsi, 2003).

\section{Metode Penelitian}

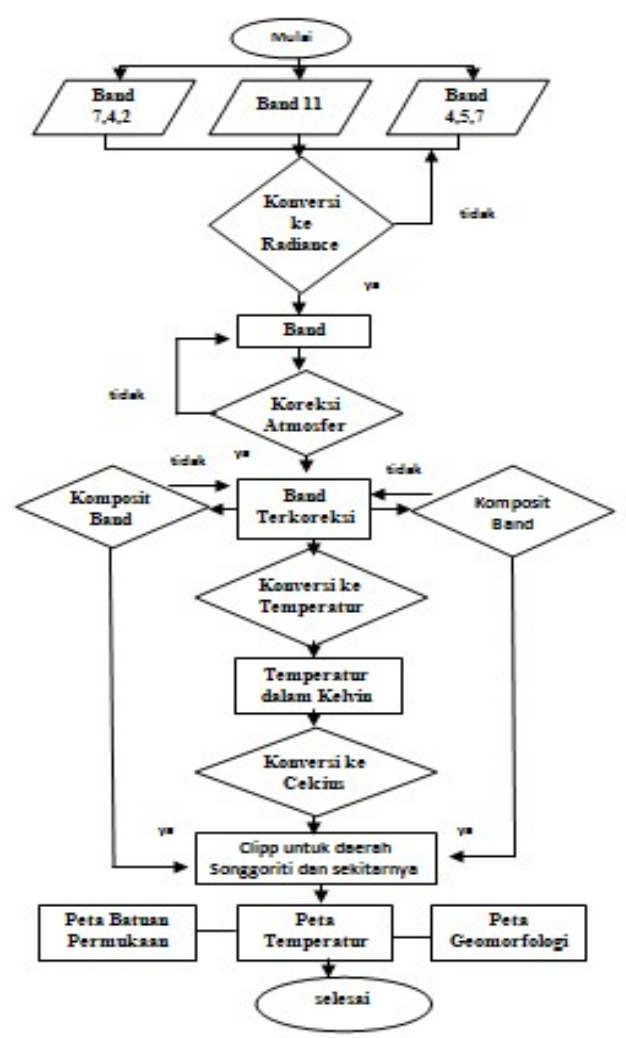

Gambar 3. Metodologi Penelitian

Metodologi penelitian ini dijelaskan pada Gambar 3. Data landsat 8 band 11 memiliki rentang panajang gelombang $(11,50-12,51 \mu \mathrm{m})$ yang diunduh melalui website earth explorer pada januari 2017. Data ini diperbarui oleh badan geologi amerika (USGS) pada januari 2017. Dengan bantuan software beam visat setiap piksel digital number dari band 11 dikonversikan ke TOA radiance melalui persamaan (1). Untuk data citra lainnya yaitu band $4,5,7,2$ juga diunduh di website yang sama.

\section{HASIL DAN PEMBAHASAN}

Citra satelit landsat 8 dalam penelitian ini menggunakan koordinat DMS (degree minute and second) datum WGS84 dengan tipe data raster. Hasil pengolahan data band citra landsat 8, didapatkan peta struktur, peta temperatur permukaan tanah dan peta batuan permukaan yang digunakan sebagai informasi daerah atau titik prospek panas bumi.

\section{Peta Geomorfologi}

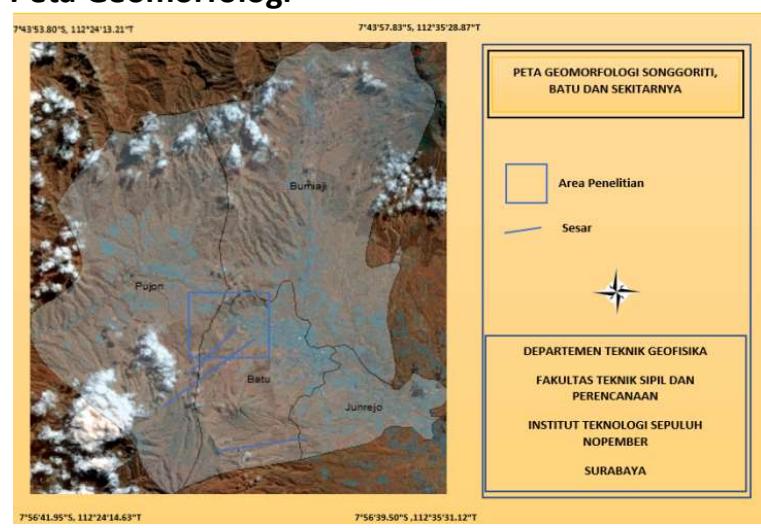

Gambar 4. Peta Struktur Daerah Batu dan Sekitarnya

Data yang digunakan untuk memetakan struktur adalah komposit band 4 , band 5 dan band 7. Komposit band ini memiliki rentang panjang gelombang yang lebar sehingga dapat mendeteksi kenampakkan struktur geologi. Analisis struktur dilakukan dengan cara menganalisis kelurusan yang terlihat pada Gambar 4. Dilakukan penarikan garis pada kemelurusan-kemelurusan yang tampak. Analisis kelurusan ini dilakukan untuk mendapatkan lokasi yang diperkirakan sebagai patahan yang dikorelasikan dengan peta geologi daerah penelitian dan kontras warna peta struktur dengan indikasi kemelurusan. Dari Gambar 4, didapatkan bahwa terdapat 2 patahan dominan dilokasi penelitian (tanda garis biru). Adanya patahan disekitar vulkanisme (gunung panderman) dapat dijadikan indikator bahwa daerah tersebut memiliki prospek panas bumi. Patahan ini diasumsikan menjadi media fluida panas yang muncul ke permukaan. 


\section{Peta Temperatur Permukaan Tanah}
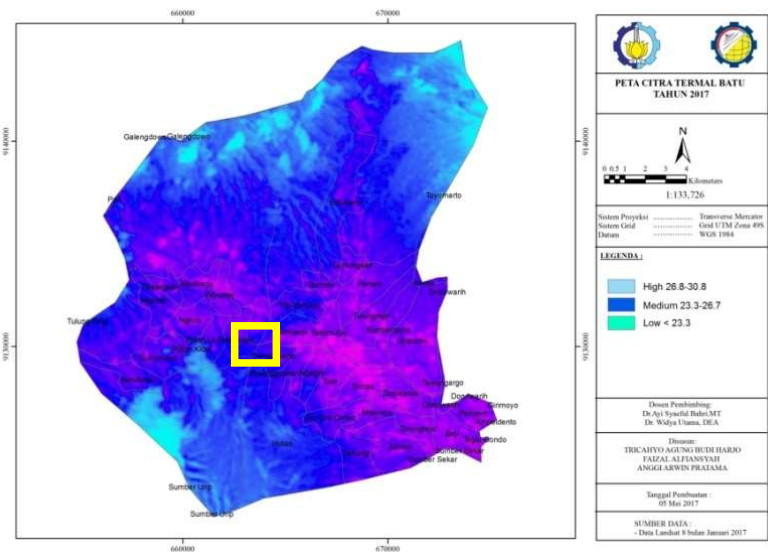

Gambar 5. Peta Temperatur Permukaan Tanah

Data yang digunakan untuk memetakan temperatur tanah adalah band 11 (11,50 $12,51 \mu \mathrm{m})$. Rentang panjang gelombang ini merupakan jendela atmosfer gelombang elektromagnetik inframerah termal. Pada panjang gelombang tersebut hambatan atmosfer relatif kecil, sehingga energi termal dapat melaluinya. Sensor termal merekam energi pancaran bukan energi kinetik benda. Energi pancaran benda lebih kecil daripada energi kinetiknya. Nilai temperatur akhir yang didapatkan pada pengolahan band 11 (termal) ini memiliki rentang $11,7164^{\circ} \mathrm{C}-30,084^{\circ} \mathrm{C}$. Daerah di sekitar manifestasi memiliki pancaran temperatur yang lebih tinggi dibandingkan dengan daerah sekitarnya yaitu pada daerah kotak kuning Gambar 5. Untuk meminimalkan ambiguitas citra termal maka dilakukan korelasi dengan peta geologi Gambar 2 . Daerah yang memiliki struktur patahan diidentifikasi sebagai daerah yang menjadi media manifestasi ke permukaan. Disekitar patahan, terdapat pancaran temperatur tinggi Gambar 5.

\section{Peta Batuan Permukaan}

Pembuatan citra komposit batuan permukaan menggunakan 3 saluran yaitu band 7 , band 4 dan band 2 , metode ini untuk mengidentifikasi penyebaran batuan yang mengalami alterasi (ubahan). Pembuatan komposit ini disesuaikan dengan panjang gelombang yang menonjolkan litologi dan struktur yaitu band 7 .

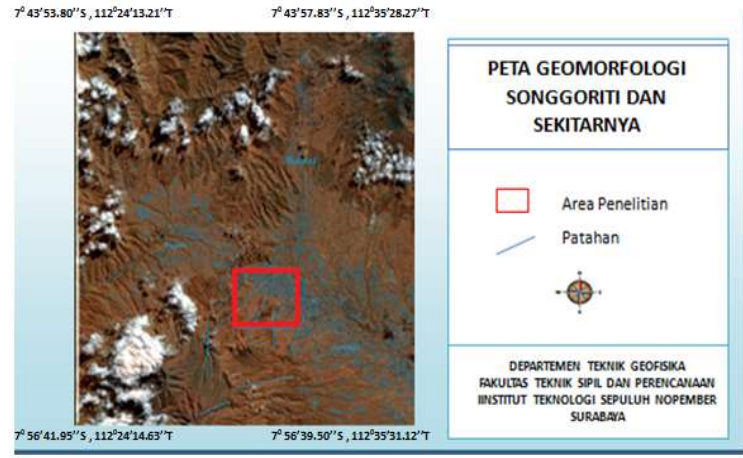

Gambar 6. Batuan Permukaan Batu dan Sekitarnya

Daerah penelitian memiliki indikasi persebaran batuan alterasi berdasarkan kontras atau perbedaan warna (tanda panah) yang terdapat pada Gambar 6. Berdasarkan korelasi peta geologi Gambar 2 daerah ini dekat dengan indikasi patahan dominan di formasi butak kawi (qpkb) dan juga manifesatasi air panas Songgoriti. Hal ini menjadi informasi untuk menentukan titik persebaran batuan teralterasi.

\section{Simpulan}

Terdapat 2 patahan dominan yang terdapat di daerah penelitian, daerah prospek panas bumi di Songgoriti, Batu ditandai dengan manifestasi air panas yang memiliki titik pancaran tinggi yaitu temperatur sekitar $30,084{ }^{\circ} \mathrm{C}$ berdasarkan citra termal. Di daerah penelitian terdapat indikasi adanya batuan teralterasi berdasarkan peta batuan permukaan. Batuan ini diindikasikan akibat adanya interaksi fluida hidrotermal dengan batuan sekitarnya.

\section{Saran}

Penelitian ini dapat dikembangkan untuk membuat rancangan desain pengukuran metode geofisika dalam mengidentifikasi daerah prospek panas bumi Songgoriti.

\section{DAFTAR PUSTAKA}

Badan Beologi, (2009). Potensi Energi Panas Bumi Indonesia. PSDG,Bandung

Barsi, (2013).An atmospheric Correction Parameter Calculator for a Single Thermal Band EarthSensing Instrument. IEE

Bernstein, R.,2013. Image Geometry and Recti_cation. Chapter 21 in The Manual of Remote Sensing R. N. 
Colwell, ed., Bethesda, MD.American Society of Photogram-metry, 1:875-881.

Danoedoro,Projo.,2016. Pengolahan Citra Digital : Teori dan Aplikasinya Dalam Bidang Penginderaan Jauh. Fakultas Geografi UGM. Yogyakarta. Geoscience and Remote Sensing.

Nuha. 2012.Pemodelan Struktur Bawah Permukaan Daerah Sumber Air Panas Songgoriti Kota Batu Berdasarkan Data Geomagnet. Jurnal Neutrino.

Purwanto, M.S., Bashri, A., Harto, M., Syahwirawan, Y., 2016. Citra Satelit Landsat $8+$ Tris Sebagai Tinjauan Awal Dari Manifestasi Panas Bumi Di Wilayah Gunung Argopura. J. Geosaintek 3, 1316.

Rina Candra Noor Santi. 2011. Teknik Perbaikan Kualitas Citra Satelit Cuaca dengan Sataid Volume 16, No.2.

Sofani,Riski.(2011).Delineasi Prospek panas bumi daerah Tiris Probolinggo dan sekitarnya dengan analisa citra satelit landsat 7 ETM+. Fisika. ITS Surabaya

Utama, W., Bahri, A.S., Warnana, D.D., 2012. Analisis Citra Landsat ETM+ untuk Kajian Awal Penentuan Daerah Potensi Panas Bumi di Gunung Lamongan, Tiris, Probolinggo. JFA J. Fis. Dan Apl. 8, 120103|14. https://doi.org/10.12962/j24604682.v8i1.858.

Wahyu Sukartono. 2017. Tekhnik Perbaikan Data Digital (Koreksi dan Penajaman) Citra Satelit. Buletin Teknik Pertanian Vol 7 No.1

Website earthexplorer.com dibuka pada 24 januari 2017 , 23:12 


\section{LAMPIRAN}
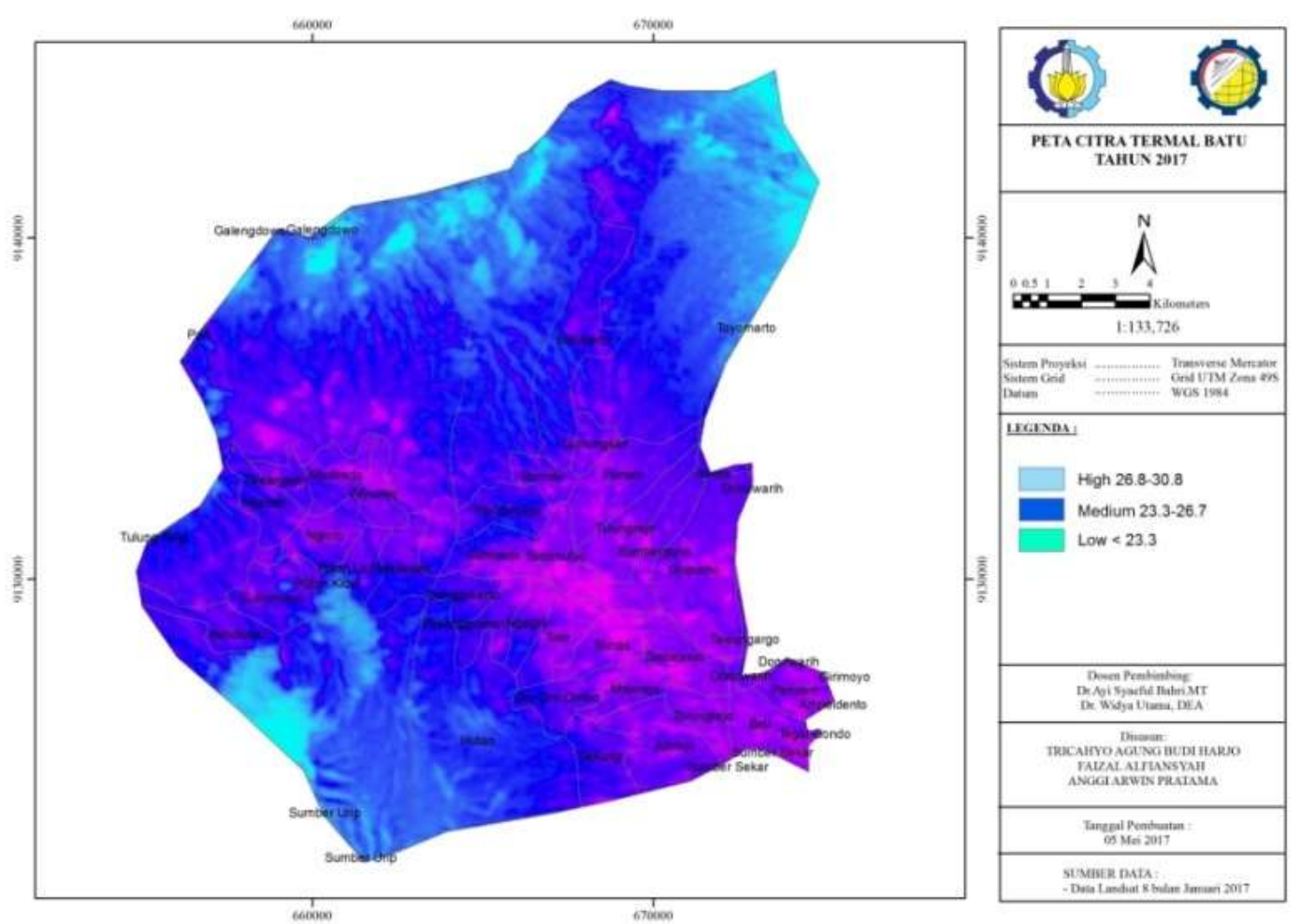

Peta Temperatur Permukaan Tanah

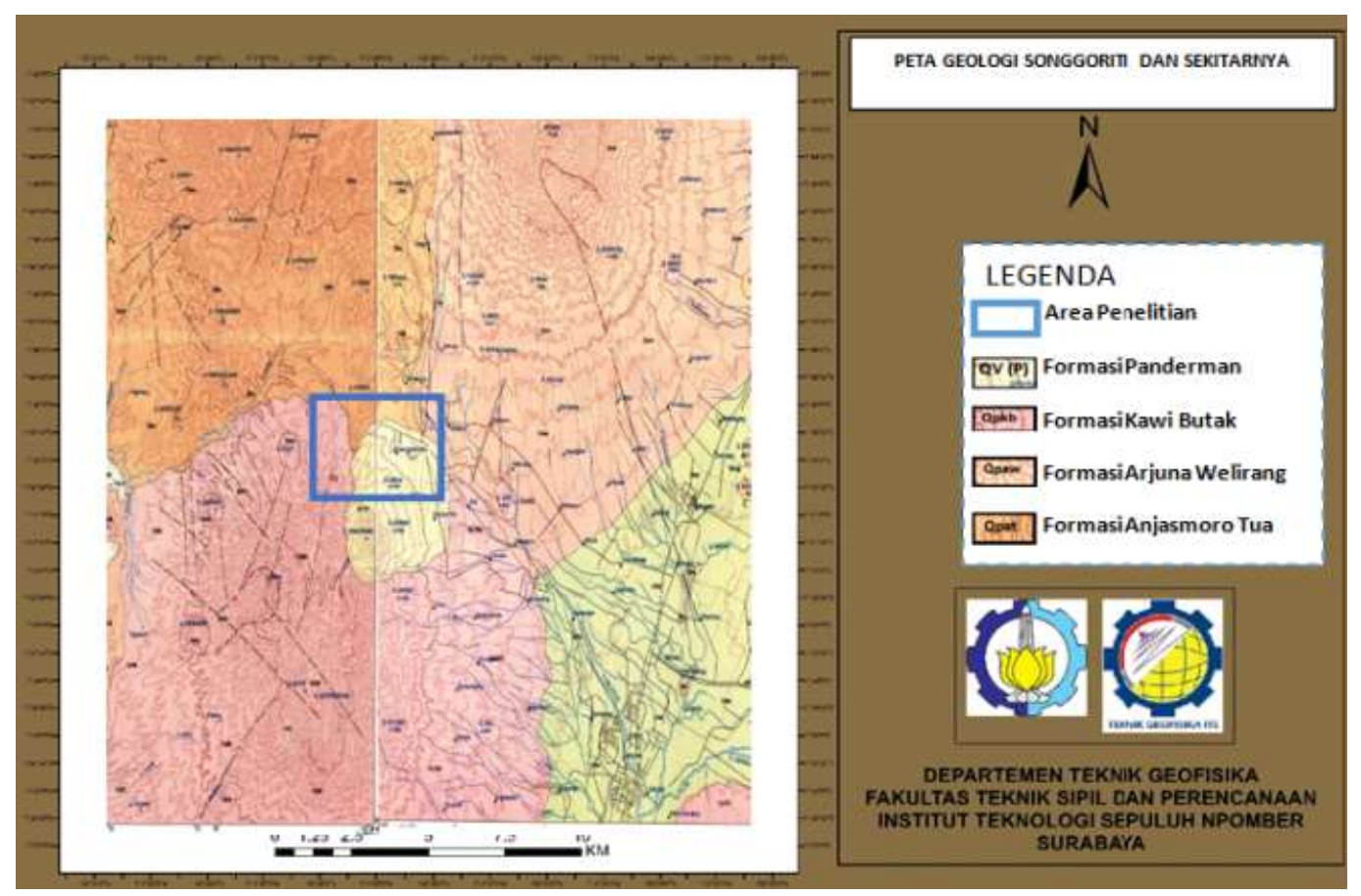

Peta Geologi Batu (Modifikasi Lembar Kediri-Batu,Santosa1992) 